\title{
Perioperative Complications and Clinical Outcomes in Patients with Congenital Cyanotic Heart Disease Undergoing Surgery for Brain Abscess
}

\author{
Smita Vimala ${ }^{1}$ Mathangi Krishnakumar ${ }^{2}$ Amit Goyal² Kamath Sriganesh ${ }^{2} \quad$ G. S. Umamaheswara Rao ${ }^{2}$ \\ Address for correspondence Kamath Sriganesh, DM, \\ Department of Neuroanesthesia and Neurocritical Care, \\ Neurosciences Faculty Block, 3rd Floor, National Institute of Mental \\ Health and Neurosciences, Bangalore 560029, Karnataka, India \\ (e-mail: drsri23@gmail.com).

\footnotetext{
${ }^{1}$ Division of Neuroanaesthesiology, Department of Anaesthesia, Sree Chitra Tirunal Institute for Medical Sciences and Technology, Trivandrum, Kerala, India National Institute of Mental Health and Neurosciences, Bangalore, Karnataka, India
} \\ ${ }^{2}$ Department of Neuroanesthesia and Neurocritical Care,
}

J Neurosci Rural Pract:2020;11:375-380

\begin{abstract}
Keywords

- congenital cyanotic heart disease

- brain abscess

- anesthesia

- neurosurgery

- outcomes

- complications

Background Brain abscess is a rare neurological complication in patients with congenital cyanotic heart disease (CCHD). Perioperative complications are high in patients with CCHD. We evaluated incidence of and risk factors for perioperative complications and their impact on clinical outcomes in patients with CCHD undergoing brain abscess surgery with monitored anesthesia care (MAC) or general anesthesia (GA).

Methods In this single-center retrospective cohort study, data were collected from consecutive patients with CCHD who presented with brain abscess and underwent surgery from January 2006 to December 2018. Data regarding demographics, type of CCHD, signs and symptoms of brain abscess and CCHD, type and duration of surgery, details of anesthesia, perioperative complications, and clinical outcomes were collected. Chi-square test was used to analyze nonparametric data and student $t$-test for parametric data.

Results Of the 402 patients with brain abscess, data of 34 patients with CCHD who underwent brain abscess surgery were analyzed. The mean age at presentation of brain abscess was $15.8 \pm 10.8$ years and duration of symptoms was $17.3 \pm 15.5$ days. The incidence of perioperative complications was $82.4 \%$ (28/34 patients). Seven patients $(20.6 \%)$ developed perioperative cyanotic spells which led to cardiac arrest in 5 patients (14.7\%) and death in 2 patients (5.9\%). Patients on cardiac medications and with high heart rate had higher incidence of cyanotic spells and mortality. Technique of anesthesia did not affect cardiac and neurological outcome.

Conclusions Perioperative complications are high after brain abscess surgery in patients with CCHD. Perioperative characteristics and outcomes were similar with MAC and GA techniques.
\end{abstract}

\section{Introduction}

With advances in medical facilities and improvement in surgical techniques, number of patients with congenital cyanotic heart disease (CCHD) attaining adulthood is increasing. ${ }^{1}$ These patients are a high-risk group for surgery and anesthesia.
Despite advances in monitoring and anesthesia techniques, presence of CCHD increases the risk of perioperative complications. ${ }^{2}$ Mortality in patients with CCHD undergoing noncardiac procedures is reported to be 16 to $19 \%$, highlighting the importance of preoperative optimization and good perioperative care in this vulnerable population. ${ }^{3}$ 
The important neurological complications associated with CCHD are brain abscess (5-18\%) and cerebrovascular events (13.6\%) with microthrombi contributing to the formation of brain abscess. ${ }^{4,5}$ Neurological deterioration due to increased intracranial pressure (ICP) from brain abscess and strategies adopted for managing raised ICP adversely affect hemodynamic status of these patients. Vomiting and decreased oral intake from deteriorating consciousness due to raised ICP contributes to dehydration, while treatment with mannitol and diuretics further deplete the intravascular volume. This can increase the risk of hyperviscosity, thrombosis, cyanotic spells, and hemodynamic collapse. The stress caused by fever, sepsis, and seizures associated with brain abscess further increases the probability of cyanotic spells. Additionally, altered consciousness causing respiratory depression and hypercarbia, or hyperventilation therapy for ICP management can lead to alteration in the cardiac shunt fraction. ${ }^{6}$ The presence of immune-compromise leads to multiple abscesses and their rupture into the cerebral ventricles contributes to increased surgical complications and morbidity. ${ }^{7}$

Earlier studies have assessed the surgical risk factors for adverse outcomes in these patients. Despite being considered as a high-risk group for anesthesia, very little is known regarding the influence of anesthetic technique and drugs, and manifestations emanating from coexisting cardiac condition such as cyanotic spells, hyperviscosity, and coagulation abnormalities on the perioperative outcome of these patients. Both monitored anesthesia care (MAC) and general anesthesia (GA) are used as anesthetic techniques for surgical management of brain abscess in patients with CCHD. This study aimed to evaluate the incidence of perioperative complications and their impact on clinical outcomes in patients with CCHD undergoing surgical treatment of brain abscess. We also aimed to compare perioperative characteristics between patients undergoing surgery with MAC and GA.

\section{Methods}

This single-center retrospective cohort study was conducted at the National Institute of Mental Health and Neurosciences (NIMHANS), a tertiary care neurosciences hospital in southern India. Approval was obtained from the NIMHANS ethics committee (NIMHANS/IEC/2018 dated October 12, 2018) and the need for informed consent was waived off. We included all patients with CCHD who presented with brain abscess and underwent surgery over a 13-year period from January 2006 to December 2018. We excluded patients with brain abscess who did not have CCHD or when brain abscess was managed conservatively.

Data were collected from patients' medical records and included details entered by neurosurgeons, nurses, anesthesiologists, intensivists, and cardiologists. The data included information about demographics, clinical details such as type of CCHD, signs and symptoms of brain abscess and CCHD, laboratory parameters, imaging findings (echocardiogram and computed tomography [CT]), details of perioperative drugs, type of surgery (burr hole evacuation [BHE) vs. craniotomy) and anesthesia (MAC vs. GA), redo surgery, and Glasgow Coma Scale (GCS) score at discharge. The outcome parameters assessed were perioperative complications especially incidence of cyanotic spells, duration of hospital stay, and mortality.

\section{Statistical Analysis}

We described variables as means (standard deviations), number (percentages), or median (interquartile range) as applicable. SPSS software (IBM SPSS Statistics, version 24, SPSS Inc., Chicago, IL, United States) was used for the statistical analysis. Univariate analysis was performed using student $t$-test for parametric data and chi-square test for nonparametric data to test the significant difference between the outcome groups. Multivariate analysis was performed using binary logistic regression for parameters significant $(<0.05)$ on univariate analysis. A p value of $<0.05$ was considered as statistically significant.

\section{Results}

During the study period (2006-2018), 402 patients with brain abscess were admitted to our hospital and underwent surgery. Data of 34 patients who had associated CCHD were analyzed. The details of patient flow into the study enrollment are depicted in -Fig. 1.

Twenty-four (70.6\%) patients were children (age < 18 years) and the rest were adults. The mean age at presentation with brain abscess was $15.8 \pm 10.8$ years and duration of symptoms of brain abscess before admission was $17.3 \pm 15.5$ days. Majority of the patients were male (25/34, 73.5\%). Twenty-four (70.6\%) patients had complex CCHD while in 10 patients $(29.4 \%)$ the cause of right-to-left shunt was development of Eisenmenger syndrome. None of the patients had undergone prior surgical correction of the primary cardiac defect. Seven patients $(20.6 \%)$ were receiving cardiac medications ( $\beta$ blockers and sildenafil). The commonest location of abscess was frontoparietal region (70.6\%). Two (5.9\%) patients presented with infratentorial abscess. The data regarding patient characteristics are presented in - Table 1. Twenty-four patients (70.6\%) underwent BHE of brain abscess whereas craniotomy was performed in 10 patients $(29.4 \%)$ at their initial presentation. Eleven patients (32.4\%) required redo surgery. Redo surgery was more frequent after BHE.

The incidence of perioperative complications was very high with $28 / 34$ patients ( $82.4 \%$ ) developing complications. Many patients developed more than one complication. The most common complication was residual abscess which occurred in 16 patients (47.1\%) of which 11 patients (32.4\%) underwent redo surgery. None of the patients had any coagulation abnormality. The details of perioperative complications are given in - Table 2.

Seven patients $(20.6 \%)$ developed cyanotic spells in the perioperative period which led to cardiac arrest in 5 patients (14.7\%) and death in 2 patients (5.9\%). The factors associated with development of cyanotic spells on univariate analysis are given in -Table 3 . None of the factors were however statistically significant on multivariable analysis. The occurrence of cyanotic spells led to increased occurrence of postoperative ventilation, cardiac arrest, death, and lower GCS score on discharge. 


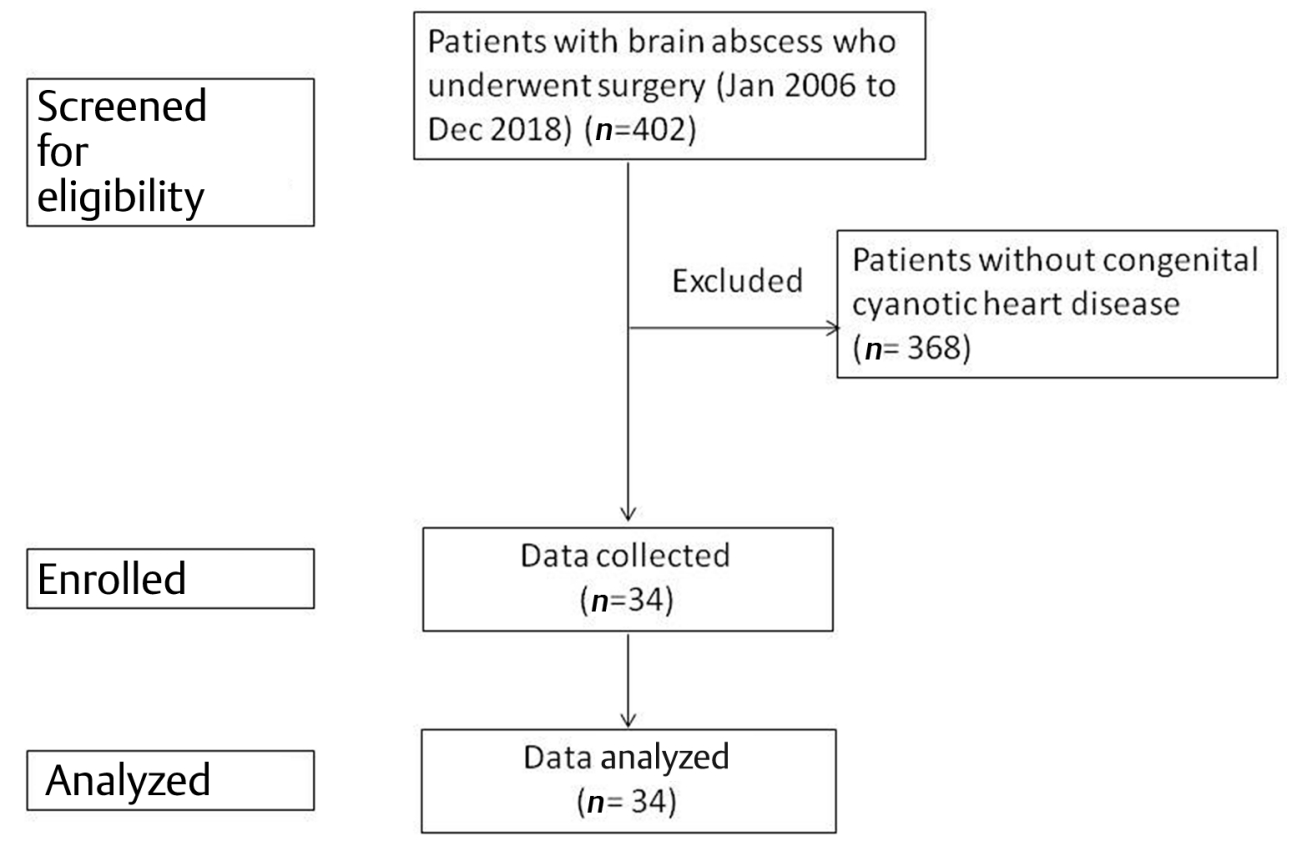

Fig. 1 Flow diagram depicting flow of patients into the study.

Table 1 Characteristics of patients with congenital cyanotic heart disease undergoing brain abscess surgery

\begin{tabular}{|l|l|l|}
\hline Parameters & N=34 & Percentage \\
\hline Male gender & 25 & 73.5 \\
\hline $\begin{array}{l}\text { Eisenmenger syndrome on } \\
\text { echocardiogram }\end{array}$ & 10 & 29.4 \\
\hline $\begin{array}{l}\text { Complex congenital heart disease } \\
\text { on echocardiogram }\end{array}$ & 24 & 70.6 \\
\hline Clubbing & 28 & 82.4 \\
\hline Cyanosis & 24 & 70.6 \\
\hline Cyanotic spells & 16 & 47.1 \\
\hline History of palpitation & 12 & 35.3 \\
\hline Recurrent respiratory infection & 12 & 35.3 \\
\hline Dyspnea on exertion & 21 & 61.8 \\
\hline Perioperative cardiac medication & 7 & 20.6 \\
\hline Altered consciousness & 20 & 58.8 \\
\hline Perioperative fever & 25 & 73.5 \\
\hline Perioperative seizures & 15 & 44.1 \\
\hline $\begin{array}{l}\text { Midline shift on computed } \\
\text { tomography scan }\end{array}$ & 25 & 73.5 \\
\hline $\begin{array}{l}\text { Cerebral edema on computed } \\
\text { tomography scan }\end{array}$ & 33 & 97.1 \\
\hline
\end{tabular}

Twenty-five patients (73.5\%) underwent initial surgery under GA whereas MAC was provided for 9 patients (26.5\%). The characteristics of patients who received GA and MAC are shown in - Table 4 . Though there were significant differences between the two anesthetic techniques for perioperative variables on univariable analysis, these differences were not significant on multivariable analysis. Ketamine was the most common anesthetic agent (61.8\%) used in combination with propofol or fentanyl for
Table 2 Perioperative complications during brain abscess surgery

\begin{tabular}{|c|c|}
\hline Complications & $N=28(82.4)$ \\
\hline \multicolumn{2}{|l|}{ Intraoperative } \\
\hline Bradycardia & $4(11.8)$ \\
\hline Hypotension & $4(11.8)$ \\
\hline Cyanotic spells & $1(2.9)$ \\
\hline Blood loss requiring transfusion & $4(11.8)$ \\
\hline Seizures & $1(2.9)$ \\
\hline \multicolumn{2}{|l|}{ Postoperative } \\
\hline Cyanotic spells & $7(20.6)$ \\
\hline Hypotension & $2(5.9)$ \\
\hline Postoperative ventilation & $4(11.8)$ \\
\hline Cardiac arrest & $5(14.7)$ \\
\hline Death & $2(5.9)$ \\
\hline Fever & $10(29.4)$ \\
\hline Residual abscess & $16(47.1)$ \\
\hline Hyponatremia & $16(47.1)$ \\
\hline Seizures & $2(5.9)$ \\
\hline Hematoma & $1(2.9)$ \\
\hline Respiratory distress & $2(5.9)$ \\
\hline Others $^{\mathrm{a}}$ & $3(8.8)$ \\
\hline
\end{tabular}

Note: Values expressed as $n(\%)$.

aOthers: Steven Johnson syndrome-1, cortical venous thrombosis-1, hydrocephalic attack-1; many patients had more than one complication, hence number of complications exceeds that of patients.

induction of anesthesia for both GA and MAC. Fourteen patients $(41.1 \%)$ received thiopentone in combination with ketamine or fentanyl. Fentanyl was the most common opioid used (76.4\%). All patients received local anesthetic infiltration with combination of lignocaine and bupivacaine at the incision site. 
All patients received antiepileptic medication, 31 (91\%) patients received osmotherapy with mannitol and dexamethasone was administered to 16 (47\%) patients in the perioperative period as part of medical management for brain abscess. A third generation cephalosporin and aminoglycoside antibiotics were administered empirically till microbiological reports were available. Sixteen patients $(47.1 \%)$ had their cardiac medication modified or initiated in the perioperative period. Nonhemolytic streptococcus (35.3\%) and Bacteroides (14.7\%) were the most common organisms isolated from abscess while in $13(38 \%)$ patients culture was sterile.

The mean duration of hospital stay was $8.9 \pm 7.8$ days. The main factor that contributed to prolonged hospital stay ( $>1$ week) was the need to optimize the cardiac function with

Table 3 Factors associated with perioperative cyanotic spells on univariate analysis

\begin{tabular}{|l|l|l|l|}
\hline Parameters & Spells $(\boldsymbol{n}=7)$ & No spells $(\boldsymbol{n}=27)$ & $p$-Value \\
\hline Cyanosis & $7(100)$ & $17(63)$ & 0.05 \\
\hline History of palpitations & $0(0)$ & $12(44.4)$ & $0.02^{\mathrm{a}}$ \\
\hline Cardiac medication & $5(71.4)$ & $2(7.4)$ & $<0.001^{\text {a }}$ \\
\hline Intraoperative complications & $4(57.1)$ & $5(18.5)$ & $0.03^{\mathrm{a}}$ \\
\hline Postoperative ventilation & $3(42.9)$ & $1(3.7)$ & $0.004^{\text {a }}$ \\
\hline Cardiac arrest & $5(71.4)$ & $0(0)$ & $<0.001^{\text {a }}$ \\
\hline Death & $2(28.6)$ & $0(0)$ & $0.004^{\text {a }}$ \\
\hline Baseline heart rate & $110.00(26.8)$ & $79.30(2.8)$ & $0.003^{\text {a }}$ \\
\hline Postoperative oxygen saturation & $87.29(5.7)$ & $92.07(6.3)$ & 0.08 \\
\hline Postoperative hematocrit & $34.93(8.4)$ & $48.10(9.8)$ & 0.08 \\
\hline Discharge Glasgow Coma Scale & $13(2)$ & $14(1)$ & $0.001^{\text {a }}$ \\
\hline
\end{tabular}

Note: Values expressed as $n$ (\%) or means ( \pm standard deviations) or median (interquartile range).

${ }^{a} p$-Value $<0.05$.

Table 4 Characteristics of patients managed with two different anesthetic techniques during first surgery

\begin{tabular}{|l|l|l|l|}
\hline Parameters & $\begin{array}{l}\text { Monitored anesthesia care } \\
(\boldsymbol{n}=9)\end{array}$ & $\begin{array}{l}\text { General anesthesia } \\
(\boldsymbol{n}=25)\end{array}$ & $p$-Value \\
\hline Cyanotic spells & $8(88.9)$ & $8(32)$ & $0.003^{\mathrm{a}}$ \\
\hline Cardiac medications & $4(44.4)$ & $3(12)$ & $0.03^{\mathrm{a}}$ \\
\hline $\begin{array}{l}\text { Oxygen saturation with oxygen } \\
\text { administration }\end{array}$ & $90.8(7.8)$ & $95.0(5.4)$ & $0.08^{\mathrm{a}}$ \\
\hline Residual abscess & $7(77.8)$ & $9(36)$ & $0.03^{\mathrm{a}}$ \\
\hline Systemic complications & $6(66.7)$ & $6(24)$ & $0.02^{\mathrm{a}}$ \\
\hline Hospital stay (days) & $13.4(8.9)$ & $7.28(6.8)$ & $0.04^{\mathrm{a}}$ \\
\hline Discharge Glasgow Coma Scale & $13(2)$ & $14(1)$ & $0.04^{\mathrm{a}}$ \\
\hline Burr hole surgery & $9(100)$ & $15(60)$ & $0.02^{\mathrm{a}}$ \\
\hline Repeat surgery & $7(77.8)$ & $4(16.7)$ & $0.001^{\mathrm{a}}$ \\
\hline
\end{tabular}

Note: Values expressed as $n(\%)$.

${ }^{a} p$-Value $<0.05$

Table 5 Factors associated with prolonged hospital stay

\begin{tabular}{|l|l|l|l|l|l|l|}
\hline \multirow{2}{*}{ Parameter } & \multicolumn{3}{|c|}{ Univariate analysis } & \multicolumn{3}{c|}{ Multivariate analysis } \\
\cline { 2 - 7 } & $\begin{array}{l}\text { Hospital stay } \\
\leq 7 \text { days }(\boldsymbol{n}=\mathbf{2 0})\end{array}$ & $\begin{array}{l}\text { Hospital stay } \\
\mathbf{7} \text { days }(\boldsymbol{n}=14)\end{array}$ & $\boldsymbol{p}$-Value & $p$-Value & Odds ratio & $\begin{array}{l}\text { 95\% confidence } \\
\text { interval for odds ratio }\end{array}$ \\
\hline Burr hole surgery & $11(55)$ & $13(92.9)$ & $0.017^{\mathrm{a}}$ & 0.37 & 4.56 & $0.16-128.53$ \\
\hline Residual abscess & $5(25)$ & $11(78.6)$ & $0.002^{\mathrm{a}}$ & 0.42 & 4.29 & $0.12-150.29$ \\
\hline Redo surgery & $2(10)$ & $9(64.2)$ & $0.001^{\mathrm{a}}$ & 0.52 & 3.08 & $0.09-98.89$ \\
\hline Perioperative cardiac drugs & $4(20)$ & $12(85.7)$ & $0.001^{\mathrm{a}}$ & $0.04^{\mathrm{a}}$ & 21.01 & $1.15-382.13$ \\
\hline Seizures & $6(30)$ & $9(69.3)$ & $0.04^{\mathrm{a}}$ & 0.08 & 16.50 & $0.65-416.99$ \\
\hline Systemic complications & $4(20)$ & $8(57.1)$ & $0.02^{\mathrm{a}}$ & 0.76 & 1.45 & $0.13-16.23$ \\
\hline Persistent fever & $3(15)$ & $7(50)$ & $0.02^{\mathrm{a}}$ & 0.32 & 5.56 & $0.18-167.24$ \\
\hline
\end{tabular}

Note: Values expressed as $n(\%)$.

${ }^{a} p$-Value $<0.05$. 
cardiac medications in the perioperative period (odds ratio 21.01, 95\% confidence interval 1.15-382.13). The details of patients with prolonged hospital stay are given in - Table $\mathbf{5}$.

\section{Discussion}

Presence of CCHD is one of the predisposing factors for occurrence of brain abscess, especially in pediatric population. ${ }^{8}$ The advent of CT imaging helped reduce the mortality associated with brain abscess from $40-60 \%$ to $0-10 \% .{ }^{9}$ But the mortality among the subset of patients with CCHD presenting with brain abscess remains high. Baum et al noted that presence of congenital heart disease (CHD) increases odds of 30-day mortality by 3.5 times in children requiring noncardiac surgery and mortality remains high even for minor procedures. Further, children with more serious heart disease had higher risk of mortality than those with less severe disease. ${ }^{10}$ Data from the Pediatric Perioperative Cardiac Arrest Registry also states that $34 \%$ of the perioperative cardiac arrests occurred in children with heart disease. ${ }^{3}$ The arrests occurred mostly following non-cardiac surgeries and, as the authors stated, were more likely to be due to cardiovascular causes. Flick et al observed that $88 \%$ of children who developed perioperative cardiac arrest had CHD and that majority of perioperative cardiac arrests were caused by factors not attributed to anesthesia. ${ }^{11}$

The incidence of perioperative complications was extremely high in our study with $28 / 34$ (82.4\%) patients developing at least one complication and many developing more than one complication. Among all the perioperative complications, cyanotic spells was the most important complication which contributed to adverse outcomes in our study. Seven patients $(20.6 \%)$ developed cyanotic spells in the perioperative period which led to cardiac arrest in 5 patients $(14.7 \%)$ and death in 2 patients (5.9\%). This is similar to the incidence of periprocedural cyanotic spells of $17 \%$ as reported by Prusty et al in patients with CCHD and brain abscess, with an overall mortality of $13 \%{ }^{12}$ The most important factors associated with the occurrence of perioperative cyanotic spells in our study were perioperative cardiac medications and high heart rate. The presence of raised ICP may interfere with the intake or absorption of enteral cardiac drugs and render patients susceptible to cyanotic spells during stress of brain infection and surgery. The high heart rate compromises coronary diastolic flow and can lead to adverse cardiac events.

Mortality associated with brain abscess is reported to be 0 to $10 \%$ and the incidence of morbidity is also 26 to $60 \%{ }^{12,13}$ The treatment of brain abscess is multimodal with parenteral antibiotics for smaller abscess and aspiration or surgical drainage for larger abscesses. ${ }^{14}$ For multiloculated abscess cavities that do not respond to antibiotic treatment, surgical excision is advocated. ${ }^{9}$ The treatment offered for brain abscess in patients with CCHD seems to be less aggressive with aspiration of the abscess and antibiotics, but recently more patients are being subjected to surgical excision. ${ }^{15}$ None of our patients required redo surgery for residual abscess when excision of abscess was performed by craniotomy under GA. However, all patients with redo surgeries underwent prior
BHE of abscess and these patients were sicker, had lower GCS score on presentation and had history of cyanotic spells. The duration of BHE was shorter; however, they had higher incidence of residual abscess and longer hospital stay. Although previous reports document increased incidence of pulmonary hypertensive crisis in intubated patients, our craniotomy patients tolerated GA well without increased occurrence of perioperative complications. ${ }^{16}$

The largest series of brain abscess in patients with CHD was reported by Takeshita et al which included 103 patients. ${ }^{17}$ They found that patients with poor outcomes were older, had intraventricular rupture of brain abscess (IVROBA) and poor neurological status on admission when compared with those with good outcomes. Presence of IVROBA was the single most risk factor that contributed to death and mortality in subset of patients with CCHD who developed brain abscess was high (13\%). In our study, the mortality was $5.9 \%$ with no patient having IVROBA. Type of surgery and technique of anesthesia were not associated with perioperative complications.

Nine patients (26.5\%) underwent surgery under MAC and the rest under GA. MAC was administered to patients with history of cyanotic spells and multiple cardiac medications. These patients initially underwent BHE of abscess and had higher incidences of residual abscess and redo surgery, longer hospital stay and lower postoperative GCS score. The poor general condition and fear of higher perioperative complications with craniotomy and GA might have been the reason for choosing less invasive surgical (BHE) and anesthetic (MAC) techniques. However, in our study, we did not find any difference in outcomes between the two anesthetic techniques; MAC and GA. The more invasive interventions (GA and craniotomy) did not lead to increased complications. Ketamine and opioids along with scalp block with local anesthetics remained the mainstay of anesthetic technique for both GA and MAC. In a recent meta-analysis, Loomba et al observed that ketamine when used in clinical doses has minimal impact on hemodynamics in children with CHD with no significant alteration of systemic and pulmonary vascular resistance. ${ }^{18}$ Recently dexmedetomidine, with its attractive profile of prevention and control of tachyarrhythmias during and after congenital heart surgery, is being increasingly used in patients with CHD to blunt sympathetic stress response, decrease anesthetic requirement and manage postoperative pain. ${ }^{19}$ MAC using dexmedetomidine was administered to one patient in our study.

This study is probably the first to evaluate the incidence of and risk factors for perioperative complications after brain abscess surgery in patients with CCHD focusing on anesthetic and surgical techniques. The major limitation of this study is the retrospective nature of data collection. Because our hospital is a single specialty neuroscience center, all our patients were referred to a cardiac center after their neurological status was stabilized resulting in loss of long-term outcome data.

\section{Clinical Implications}

In view of the findings of our study, it is apparent that both craniotomy and GA are equally safe as BHE and MAC in 
patients with CCHD for brain abscess surgery. Importantly, patients receiving GA for craniotomy had lower complications (redo surgery) and better outcomes (shorter hospital stay). Undue fear about increased mortality and morbidity from more invasive interventions (craniotomy and GA) is unwarranted. This has led to change in practice of surgical and anesthetic management for such patients in our hospital.

\section{Conclusions}

The incidence of perioperative complications is high in patients with CCHD undergoing surgery for brain abscess. Among all the complications, perioperative cyanotic spells significantly contributed to mortality. Outcomes were similar with both MAC and GA techniques of anesthesia for surgical treatment of brain abscess.

\section{Authors' Contributions}

S. V.-Data collection, statistical analyses, and initial draft. M. K.-Data collection and critical review of the manuscript. A. G.-Data collection and critical feedback of the manuscript draft.

K. S.-Revision of the manuscript and final preparation of manuscript.

G. S. U. R.-Critical review of the manuscript.

\section{Ethical Approval}

Approval for this study was obtained from the NIMHANS ethics committee (NIMHANS/IEC/2018 dated 10-12-2018).

\section{Funding}

None.

\section{Conflict of Interest}

None declared.

\section{References}

1 Ávila P, Mercier LA, Dore A, et al. Adult congenital heart disease: a growing epidemic. Can J Cardiol 2014;30(12(Suppl): S410-S419

2 van der Griend BF, Lister NA, McKenzie IM, et al. Postoperative mortality in children after 101,885 anesthetics at a tertiary pediatric hospital. Anesth Analg 2011;112(6):1440-1447

3 Ramamoorthy C, Haberkern CM, Bhananker SM, et al. Anesthesia-related cardiac arrest in children with heart disease: data from the Pediatric Perioperative Cardiac Arrest (POCA) registry. Anesth Analg 2010;110(5):1376-1382

4 Takeshita M, Kagawa M, Yonetani H, et al. Risk factors for brain abscess in patients with congenital cyanotic heart disease. Neurol Med Chir (Tokyo) 1992;32(9):667-670

5 Ammash N, Warnes CA. Cerebrovascular events in adult patients with cyanotic congenital heart disease. J Am Coll Cardiol 1996;28(3):768-772

6 Gottlieb EA, Andropoulos DB. Anesthesia for the patient with congenital heart disease presenting for noncardiac surgery. Curr Opin Anaesthesiol 2013;26(3):318-326

7 Sharma BS, Gupta SK, Khosla VK. Current concepts in the management of pyogenic brain abscess. Neurol India 2000;48(2):105-111

8 Shachor-Meyouhas Y, Bar-Joseph G, Guilburd JN, Lorber A, Hadash A, Kassis I. Brain abscess in children-epidemiology, predisposing factors and management in the modern medicine era. Acta Paediatr 2010;99(8):1163-1167

9 Moorthy RK, Rajshekhar V. Management of brain abscess: an overview. Neurosurg Focus 2008;24(6):E3

10 Baum VC, Barton DM, Gutgesell HP. Influence of congenital heart disease on mortality after noncardiac surgery in hospitalized children. Pediatrics 2000;105(2):332-335

11 Flick RP, Sprung J, Harrison TE, et al. Perioperative cardiac arrests in children between 1988 and 2005 at a tertiary referral center: a study of 92,881 patients. Anesthesiology 2007;106(2):226-237, quiz 413-414

12 Prusty GK. Brain abscesses in cyanotic heart disease. Indian J Pediatr 1993;60(1):43-51

13 Mehnaz A, Syed AU, Saleem AS, Khalid CN. Clinical features and outcome of cerebral abscess in congenital heart disease. J Ayub Med Coll Abbottabad 2006;18(2):21-24

14 Singh I, Rohilla S, Kumawat M. Twist drill aspiration of pyogenic brain abscesses: our experience in 103 cases. J Neurol Surg A Cent Eur Neurosurg 2014;75(3):189-194

15 Ashraf M, Ahmed S, Ahmad S, Hussain M. Burr hole aspiration of brain abscess in children with cyanotic heart disease. J Coll Physicians Surg Pak 2017;27(8):483-485

16 White MC. Approach to managing children with heart disease for noncardiac surgery. Paediatr Anaesth 2011;21(5):522-529

17 Takeshita M, Kagawa M, Yato S, et al. Current treatment of brain abscess in patients with congenital cyanotic heart disease. Neurosurgery 1997;41(6):1270-1278, discussion 1278-1279

18 Loomba RS, Gray SB, Flores S. Hemodynamic effects of ketamine in children with congenital heart disease and/or pulmonary hypertension. Congenit Heart Dis 2018;13(5):646-654

19 Tobias JD, Gupta P, Naguib A, Yates AR. Dexmedetomidine: applications for the pediatric patient with congenital heart disease. Pediatr Cardiol 2011;32(8):1075-1087 